\title{
PONCIÁ VICÊNCIO E O ALEGRE CANTO DA PERDIZ: TRAJETÓRIAS EM CONVERGÊNCIA SOLIDÁRIA PONCIÁ VICÊNCIO AND O ALEGRE CANTO DA PERDIZ: TRAJECTORIES IN SOLIDARITY CONVERGENCE
}

\author{
InARA DE Olivelra RodRIGUes* \\ Maiane PIRES TiGRE"
}

Resumo: Analisam-se as identidades difratadas que se refletem sobre a multiplicidade das fronteiras sociais e culturais em jogo nas obras $O$ alegre canto da perdiz (2008), de Paulina Chiziane, e Ponciá Vicêncio (2003), de Conceição Evaristo. A pesquisa, de base eminentemente bibliográfica, segue a metodologia comparativa prospectiva de Abdala Júnior (2015). Dada a atualidade de um mundo atravessado por fronteiras múltiplas, esse comparativismo proporciona a abertura ao diálogo crítico, envolvendo questões políticas e práticas culturais de Moçambique e do Brasil, afirmando-se a convergência solidária na escritura das autoras em destaque.

Palavras-chave: identidade, literatura afro-brasileira, literatura moçambicana, romance

Abstract: The aim of this article is a analyse of diffracted identities which are reflected on the many social and cultural borders at stake in the works $O$ alegre canto da perdiz (2008), by Paulina Chiziane and Ponciá Vicêncio (2003), by Conceição Evaristo. The basic bibliographical research, primarily follows the comparative methodology prospective of Abdala Júnior (2015). Given the actuality of a world traversed by multiple borders, this comparativism provides the opening to the critical dialogue, involving matters of political and cultural practices of Mozambique and Brazil, asserting itself solidary convergence in scripture of the authors featured.

Keywords: identity, afro-brazilian literature, literature of Mozambique, novel

\footnotetext{
* Professora titular do Departamento de Letras e Artes da Universidade Estadual de Santa Cruz (UESC).

${ }^{* *}$ Mestra em Letras pela Universidade Estadual de Santa Cruz (UESC).
} 


\section{onsiderações iniciais}

[...]

Mesmo que nos torturem

Havemos de voltar

Mesmo que nos expulsem

Havemos de voltar.

Mesmo que nos matem

Havemos de voltar!

Apesar desta escravatura

Havemos de voltar.

(CHIZIANE, 2008)

\section{[...]}

Da língua cortada,

digo tudo,

amasso o silêncio

e no farfalhar do meio som

solto o grito, do grito, do grito

e encontro a fala anterior,

aquela que emudecida,

conservou a voz e os sentidos

nos labirintos da lembrança.

(EVARISTO, 2008)

A resistência cultural segue o caminho da proposição de alternativas contrárias ao modelo imposto pela globalização neoliberal. Por essa perspectiva, são consideradas as razões que implicam diretamente na constituição das identidades no âmbito da pós-colonialidade, associadas às estratégias de resistência cultural. Desse modo, desenvolve-se, aqui, uma análise comparativa prospectiva, na esteira das proposições de Abdala Júnior (2014), para o cotejo dos romances Ponciá Vicêncio (2003), de Conceição Evaristo, e O alegre canto da perdiz (2008), de Paulina Chiziane. 
Para Mata (2014, p. 29), em estudo comparativo, as obras são "representativas de opções estéticas individuais, ou contextuais e circunstanciais", pois também propiciam um mergulho na "estética do diverso", revelando a riqueza das diferenças que as envolvem (SEGALEN apud MATA, 2014, p. 40). Assim, acredita-se que a literatura comparada seja o método de estudo mais adequado a ser empregado nesta investigação, na análise da literatura moçambicana em cotejo com a afro-brasileira.

Com efeito, neste trabalho, consideram-se os locais enunciativos das autoras Evaristo (2003) e Chiziane (2008), respeitando-se as particularidades e experiências culturais de cada uma. Objetiva-se, sobretudo, a partir do comparatismo literário prospectivo, articular visões de mundo contidas nas obras referidas das respectivas autoras, de forma solidária, englobando as diferenças ou continuidades históricas, a vida material, as circunstâncias sociais e políticas que as enformam, estabelecendo os fluxos culturais entre sujeitos / sujeitos.

Em relação ao método comparativo prospectivo, Abdala Júnior (2014b, p. 127) afirma:

Tenho proposto outra forma de comparatismo [...]. Um comparatismo prospectivo, pautado por relações comunitárias, um comparatismo da solidariedade, da compreensão. Comparar diante de problemáticas que nos envolvem a todos para nos conhecer naquilo que temos de próprio e em comum. Enlaces comparatistas, tendentes a relações de reciprocidade, não numa relação sujeito/objeto, mas sujeito/sujeito em aproximações e friç̧ões, tendo em conta desafios que se colocam em termos de atualidade sociocultural.

Trata-se, assim, de um comparatismo que articula atitudes comunitárias de cooperação e solidariedade; este se estabelece aqui entre as literaturas de Moçambique e do Brasil, possibilitando o trânsito de efetivas trocas culturais. Compreende-se, portanto, que apesar da existência de identidades plurais e das múltiplas fronteiras, a abertura baseada em relações de reciprocidade não só é possível como deve ser implementada a partir do trânsito dos variados fluxos culturais, tanto mais entre países que possuem "inclinações comunitárias linguístico-culturais" (ABDALA JR., 2014b, p. 125), como é o caso desses países de língua portuguesa. 
Nesse panorama, Ponciá Vicêncio e $O$ alegre canto da perdiz situam-se enquanto expressões literárias das gnoseologias do Sul metafórico, considerando-se Brasil e Moçambique respectivamente. Se com Mudimbe (2013) afirma-se uma gnose africana e, com Santos (2009), as epistemologias do Sul, entende-se procedente afirmar-se o sentido de gnoseologias do Sul como estratégia geocrítica às epistemologias ideologizantes do poder colonizador / imperialista, instauradas em espaços histórico-culturais subalternizados, como são exemplos, entre outros, Brasil e Moçambique e, consequentemente, a produção literária afro-brasileira e moçambicana.

Além disso, deve-se enfatizar "[...] o comunitarismo linguístico-cultural [que] constitui um ponto de partida político e estabelece, para nós, um 'nó', em termos de redes comunicacionais" (ABDALA JR., 2012, p. 22). Partindo de locais específicos de enunciação, essas obras traduzem um posicionamento estético-ideológico de contestação e engajamento de natureza contra-hegemônica, desempenhando o papel de "contranarrar" a trajetória do sujeito afro-brasileiro e moçambicano, nos variados contextos de exclusão. Tomando por base o estudo comparado do espaço geopolítico, essas obras literárias procedem à demarcação de campos culturais periféricos, com suas particularidades idiossincráticas, que por sua vez não são validadas, nem alcançam o pleno reconhecimento do Centro. São nesses lugares / lócus, situados nas margens, que se constroem personagens femininas negras, cujas vozes e rostos, como Ponciá e Maria das Dores, empreendem ferrenha oposição ao imperialismo epistemológico cristalizado em perspectivas eurocêntricas.

Por essa ótica, efetiva-se a possibilidade de se cruzar, nos romances em análise, os espaços marginais e a produção de discursos ideológicos afins, visando denunciar os fluxos hegemônicos transnacionais causadores da pobreza, da desigualdade social, da discriminação racial, da exploração, da opressão de gênero, entre outros. Por seu turno, a lógica da colonialidade do poder, do saber e do ser, no Brasil e em Moçambique, conflui negativamente, favorecendo "em sentido prospectivo, os horizontes e as novas fronteiras de cooperação comunitária" (ABDALA JR., 2012, p. 89). 


\section{Resistência e solidariedade nas diferenças: trajetórias convergentes}

Nos instáveis e intermináveis fluxos oceânicos, proporcionados pelo cotejo dessas duas obras provenientes de espaços diversos, mas imbuídas de "repertórios supranacionais" em comum (ABDALA JR., 2012, p. 27), a travessia, em sentido político-cultural, é indispensável. Ressalte-se que o atravessar das fronteiras físicas, epistemológicas, ideológicas, geográficas requer olhar efetivamente o outro: mirando a cultura diversa, o conjunto de crenças e costumes ignorados, os saberes locais peculiares. É preciso impulsionar, em termos de solidariedade e de valorização das diferentes realidades sociais, o fortalecimento das relações comunitárias entre esses países.

O mar constitui a distância que separa Brasil e Moçambique, todavia o afastamento se dilui na intersecção das águas, o "oceano de fronteiras (in)visíveis" (SANTOS, 2016, p. 1) que outrora sedimentava, isolava, hoje passa a ser visto com outros olhos, espelhando um esforço de efetiva aproximação (CHAVES; SECCO; MACÊDO, 2006, p. 9). A expectativa em desvelar os sinais da presença africana no Brasil parece ser crescente, exibida nos nomes, na culinária, no comportamento, nas roupas, na cultura, nos vestígios de um Brasil africano e de uma África envolta nas brumas literárias brasileiras, "como se, de repente, deixassem de existir a geografia e a história, o espaço e o tempo. E o mar fosse mentira [...] [nesse circuito das águas], ainda que o mar seja verdade" (ibid., p. 15).

No que respeita à formação identitária das personagens, encontram-se outras equivalências, especialmente no bojo das identidades femininas, atravessadas em igual medida por fraturas de gênero, classe social e etnia, considerando-se que "as questões identitárias devem ser vistas no plural" (ABDALA JR., 2012, p. 22). Assim, quer seja do grupo étnico-racial afro-brasileiro, com Ponciá, quanto moçambicano, com Maria das Dores, ambas encarnam o paradigma da resistência da mulher negra, pobre, desprestigiada; ambas compartilham fortes experiências de exclusão, a ponto de se equipararem àquilo que não é nada e ninguém. As protagonistas apresentam-se da seguinte forma: "Eu sou a Maria das Dores, aquela que ninguém vê" (CHIZIANE, 2008, p. 18). Ponciá adota gesto similar: a "[...] cabeça rodava no vazio, ela vazia se sentia sem nome. Sentia-se ninguém" (EVARISTO, 2003, p. 16), estatuindo limitações que pesam, de forma insuportável, sobre a condição do feminino negro. 
Ponciá após perder o avô, o pai, ter gerado e perdido os sete filhos, sofre com o posterior desaparecimento da mãe, Maria Vicêncio, e do irmão Luandi. Maria das Dores também passa por um intermitente processo de perdas ocorridas ao longo da sua história. São perdas familiares - Perder um filho é uma dor que mata. Perder três é algo que sepulta no mais profundo dos infernos" (CHIZIANE, 2008, p. 32), que atingem o âmago de sua subjetividade: "Mas não tenho nome. Nem sombra. Nem existência. Sou uma borboleta incolor, disforme. Das palavras conheço as injúrias, e dos gestos, as agressões. Tenho o coração quebrado" (ibid., p. 18).

Tais perdas, dentro da perspectiva do comparatismo literário prospectivo, aproximam as distintas culturas, considerando-se a situação de agudo sofrimento dessas mulheres. Deve-se, assim, examinar às circunstâncias históricas da colonização nesses dois países que subalternizam as mulheres e, tanto mais, as mulheres negras.

Nos dois romances são abundantes as cenas e fatos baseados na diferença de gênero, impingindo, de forma cortante e violenta, marginalidade às identidades de Maria das Dores e Delfina, bem como à de Ponciá Vicêncio. Vale lembrar que, no tocante à fratura de gênero em Ponciá, notam-se as sucessivas atitudes de sua objetificação sexual por parte de seu marido, dentre as quais cita-se: "deu-Ihe um violento soco nas costas, gritando-Ihe pelo nome. Ela Ihe devolveu um olhar de ódio. Pensou em [...] passar por debaixo do arco-íris e virar logo homem. Levantou-se, porém, amargurada de seu cantinho e foi preparar a janta" (EVARISTO, 2003, p. 17). No caso de Maria das Dores, seu gênero sentencia-a a uma existência preenchida de vazios e sofrimentos; por exemplo, quando a sua mãe, Delfina, negocia a virgindade da filha em troca de um feitiço para amarrar o coração do português Soares: "Dou-te a virgindade da minha filha. - O quê? És capaz? [...]. Na sua terra a mulher é peça que se compra e se vende. Selo de contrato. Moeda de troca. Hipoteca. Multa. Sobrevivência” (CHIZIANE, 2008, p. ).

Enquanto Ponciá modela o barro, Maria das Dores se reveste de barro: "Quem sou eu? Uma estátua de barro, no meio da chuva" (CHIZIANE, 2008, p. 17), referindo-se à situação da insignificância existencial a que estava submetida. Em sua luta pela sobrevivência, entretanto, ambas seguem com certas esperanças, almejando novos caminhos. A representação da fratura da pobreza escalonada na hierarquia da classe social define o ambiente de Delfina: "[...] quando abriu os olhos para a vida o mundo já era assim. Um filme sem enredo. Negros a se- 
rem castigados. Carga. Descarga. Chicote. Greves e mortes [...]. No seu sonho é senhora e habita uma cidade de pedra" (ibid., p. 77). Retrata-se, de modo semelhante, a ambiência de Ponciá repleta de carências: "Foi até a prateleira, pegou uma lata de goiabada vazia e começou a servir a comida para ele. Da panela subia cheiro algum. Teve dúvidas se comeria ou não [...]. Ponciá correu vagarosamente os olhos pelo cômodo onde moravam" (EVARISTO, 2003, p. 22).

Nos tantos enfrentamentos vivenciados pelas personagens Ponciá, Maria das Dores e Delfina, inescapavelmente pesa-lhes a cor negra, pigmento tatuado na pele dessas mulheres que as insere em cenários de grande hostilidade. De sorte que "a mulher negra buscará um filho mulato. Para aliviar o negro da sua pele como quem alivia as roupas de luto" (CHIZIANE, 2008, p. 184). O destino impiedoso de todas elas converte-se no mesmo percurso trilhado pelo feminino negro, circunstancialmente categorizado pelo assente estigma da cor, já que "uma das assimetrias de poder simbólico colonial, sabemos, foi a classificação social a partir da ideia de raça - uma justificativa da dominação dos povos à escala mundial" (ABDALA JR., 2012, p. 25). Não há que se falar em sorte, mas em má-sorte, não há que se falar em alegria, mas em infortúnios, tampouco há que se falar em mudança, tão somente em repetição da herança, em circularidade da escravidão e da exploração. Apesar disso, há, por trás de todas elas, itinerários inconfundíveis de resistência e luta por superação.

Interessa reconhecer-se que a figura de Paulina Chiziane não poucas vezes é associada à de Conceição Evaristo e vice-versa. Alguns teóricos chamam a atenção para o fato de ambas se assemelharem tanto na escrita poética quanto nas diferentes formas de narrar o feminino, exaltando essas vozes sob oclusão (DIOGO, 2010). A própria Chiziane, em entrevista à Rosália Diogo (2013), reconhece o alto grau de semelhança com Evaristo, especialmente por possuir pontos de contato e ressonâncias com as construções literárias daquela autora. As leituras das duas escritoras convergem em uma mesma direção, denunciando situações de racismo e de opressão. Essa correspondência de olhares, em que pese a multiplicidade de perspectivas temáticas específicas de cada uma delas, é reconhecida por Chiziane:

Peguei o livro Ponciá Vicêncio para ler e começo a identificar-me com ele. Li também Poemas da recordação e outros movimentos e agradei-me muito. A sonoridade me chamou a atenção também. Conceição escreve, na obra, assuntos completamente 
diferentes dos meus, mas quando fecho os olhos me vejo no Brasil e penso que poderia ter sido eu a escrever o romance. A obra me fez sentir muito próxima dela. É como se meu espírito estivesse naquela história. Recebi essa obra diretamente das mãos dela e, fisicamente, não pareço com ela, mas tem algo. Quando se olha para ela e para mim, fica a sensação de pessoas que viveram no mesmo lugar, ou são irmãs [...] A Conceição Evaristo passa por uma moçambicana, e se eu disser que ela é minha irmã mais velha ou mais nova, com certeza as pessoas acreditarão. (in CHIZIANE; DIOGO, 2013, p. 368)

Analogamente, a pedra de toque radicada na escrita literária poética de ambas se situa no caráter subversivo, sendo que tais literaturas se encaixam no bloco da resistência colonial à episteme eurocêntrica, estabelecendo uma geocrítica aos códigos literários ocidentais colonizadores. Nesse sentido, reclamam, para a vida das mulheres negras representadas em suas obras, maior visibilidade nas questões referentes à cidadania, aos direitos civis, políticos, familiares, humanos, no sentido de minimizar cada vez mais as rotas da exclusão como parte de um processo cambiado por intensos fluxos intercomunitários.

A relação entre as autoras não para por aí, ao contrário, amplia-se, enredando a vida das suas próprias personagens: como se Ponciá pudesse viver a vida de Maria das Dores e Maria das Dores sem dificuldade trocasse de existência com Ponciá, tamanha similitude na construção do perfil dessas duas personagens, fortemente marcadas pela condição de mulheres negras, habitantes das periferias do mundo. Sobre a sua conformação temática, assim esclarece Evaristo: "Eu sempre tenho dito que a minha condição de mulher negra marca a minha escrita, de forma consciente inclusive. Faço opção por esses temas, por escrever dessa forma. Isso me marca como cidadã e me marca como escritora também" (in CAZES, 2016, online). Igualmente, Evaristo transfere para a palavra oral a responsabilidade pelo surgimento da escrita literária em sua vida, destacando a importância de seu meio social constituído por mulheres negras cozinheiras, faxineiras e empregadas domésticas: "Não nasci rodeada de livros, mas rodeada de palavras. Havia toda uma herança das culturas africanas de contação de histórias". Fato que mais uma vez conecta Evaristo a Chiziane, graças ao mítico universo da oralidade que conferiu a esta última o estatuto de escritora, apesar de sua opinião contrária: "Sou contadora de estórias e não romancista. Escrevo livros com muitas estórias, estórias grandes e pequenas. Inspiro-me nos contos 
à volta da fogueira, minha primeira escola de arte" (SILVA; CHIZIANE, 2016, online).

Todavia, chama-se a atenção para o fato de que, apesar de haver profundas correspondências entre as autoras Evaristo e Chiziane, bem como entre Ponciá e Maria das Dores, não podemos situá-las no mesmo plano das suas respectivas personagens, visto que o lugar que essas escritoras ocupam atualmente, sendo conhecidas nacional e internacionalmente, garante-lhes condições sociais mais favoráveis em relação às das mulheres negras representadas nas duas obras, totalmente inseridas nas zonas de exclusão. Por certo há muito que se reconhece a efetiva distância entre a autoria e personagem e, obviamente, não se trata disso aqui - entretanto, convém destacar, numa perspectiva crítica comparativa, que, mesmo sublinhando o seu processo de escrevivência, como Evaristo define sua escrita, ou as opções temáticas de Chiziane, ambas estão num lócus enunciativo que, com proximidades vincadas em suas lutas pregressas, hoje denunciam as mazelas das mulheres que não conseguiram ou conseguem garantir devidamente sua existência.

No romance $O$ alegre canto da perdiz, Chiziane faz uma releitura crítica da cosmovisão e do comportamento social dos moçambicanos no período de instalação e vigência do processo de colonização. Vale-se, portanto, de uma literatura alternativa, cujo pano de fundo está concatenado ao desejo de poder dos portugueses, por sua vez, alimentado pela ambição dos africanos, na corrupção dos estratos sociais, no apagamento da tradição, na assimilação identitária, tendo em vista o lugar de subserviência do feminino e a ulterior possibilidade de ascensão ao mundo branco. Assim, a autora "confronta-nos, [...] com uma leitura, por um lado, pós-colonial das resultantes culturais da prática colonial e, por outro, com a indagação do papel da mulher em uma sociedade eminentemente falocrática e prepotente" (LEITE, 2013, p. 27). Trata-se de uma literatura tipicamente classificada como "literatura de gênero", caracterizadora de sentidos dialéticos promovidos por essa escrita feminina subversiva:

O tratamento dos temas sobre a "mulher" realizado por escritora pressupõe um ponto de vista alternativo e crítico também ao da escrita feita por escritores homens; a narrativa de "gênero" é uma das estratégias discursivas pós-coloniais que pressupõe implícita e explicitamente um diálogo crítico com a narrativa, majoritariamente, centralizada em uma tradição masculina. Por outro lado, permite 
um alargamento temático, tratado a partir de dentro, criando uma abertura no cânone literário africano, em formação. (ibid., p. 28)

De dentro para fora, Evaristo move-se também nesse passo, ajustando-se intencionalmente a uma escrita que dá mobilidade às suas personagens negras, trazendo a lume toda a complexidade psicológica manifesta por elas e costuradas ao universo cultural fraturado com o qual se relacionam: injustiça social, isolamento, preconceito, discriminação e racismo. Com a protagonista Ponciá, Evaristo trabalha criticamente os resquícios coloniais na trajetória de sua personagem e, por intermédio desse ato de reinvenção literária criadora "[...] transforma marginalização em poder [...]. É através do seu trabalho e dos diferentes temas que aborda que re-constrói [...] suas diferentes identidades: mulher, preta, pobre. A escrita representa assim um ato de resistência" (GONÇALVES, 2009, p. 57-58). De outro modo, poder-se-ia afirmar que "ao recusar-se à passividade, questiona a posição dos afro-brasileiros de um modo geral, especialmente das mulheres", ocasião em que também "tenta descobrir e entender suas muitas caras: preta, pobre e mulher" (ibid., p. 64). Em outras palavras, essa literatura é vista como ponto vital de liberdade e de consciência política dos sujeitos diaspóricos, servindo para alumbrar temas complexos, como por exemplo, a composição de suas muitas identidades:

Podemos entender a literatura dessas mulheres como uma arma de criatividade, palco de resistência do sujeito diaspórico, local onde questões de diáspora são levantadas, questionadas, reforçadas. Espaço onde o sujeito diaspórico [...] configura suas identidades alternativas [...] a escrita nesse caso deve ser pensada como um processo constante de auto-(re)definição. (ibid., p. 57)

Dessa tensão resulta sua crítica à inferiorização do corpo negro feminino, demarcado por sua dupla condição marginal, fundada na antinomia: corpo e sexo, enfatizando-se o aspecto negativo da diferença de gênero:

A representação literária da mulher negra ainda surge ancorada nas imagens de seu passado escravo, de corpo-procriação e/ou corpo-objeto de prazer do macho senhor. Interessante observar que determinados estereótipos de negros/as, 
veiculados no discurso literário brasileiro, são encontrados desde o período da literatura colonial. (EVARISTO, 2005, p. 52)

Situações exemplares, nesse sentido, podem ser percebidas tanto em Ponciá Vicêncio, quanto em $O$ alegre canto da perdiz, obras literárias nas quais o corpo da mulher negra se constitui como lugar de origem e fim dos desejos e impulsos sexuais masculinos. Na obra moçambicana, descreve-se a violação de Maria das Dores por Simbá através do ato bestial de negociação sexual: "Maria das Dores estava a ser violada. Extraviada. Roubada. Uma menina submetida à sádica obsessão daqueles que a deviam amar" (CHIZIANE, 2008, p. 256). Na obra brasileira, o fragmento em que Ponciá se converte na combinação de corpo-pernas: "nem quando ela o conheceu, nem quando ela e ele sorriam e se amavam ainda, Ponciá conseguiu abrir para ele algo além do que seu corpo-pernas" (EVARISTO, 2003, p. 43).

Nesses termos, atentando-se para as considerações anteriores, interessa aqui colocar em relevo a questão dos significados dessas identidades tão marcadas por fatores internos e externos de exclusão que, em sua concretude, redimensionam o campo identitário desses sujeitos excluídos. Torna-se imperativo retirar tais identidades sob difração da "escuridade", ampliando o horizonte de "eus" fragmentados frente a falaciosos outros integrados; pretendendo enxergá-los, visibilizá-los, incluí-los na terceira margem de signos identitários reconhecidos como verdadeiros retratos da resistência. Ou ainda, os vários níveis e recortes nas identidades que exigem respostas solidárias com vistas a estreitarem as alargadas fronteiras da exclusão. A fragmentação, para além da natureza cultural, impõe-se como capacidade de aceitação da diferença de gênero, diferença social e étnica, em face à homogeneizante sociedade, além de conciliar no âmbito da identidade forças inconciliáveis. Pressupõe-se uma lógica de questionamento e desestabilização da totalidade e da unidade paradigmaticamente acenada na presença do homem branco europeu; esse corte instaurado no plano identitário faz nascer sujeitos "cindidos, difratados" no tempo e no espaço, colocados em separado por serem depositários do gérmen da diversidade. Um desafio tanto aos "sujeitos integrados" quanto às polaridades sociais dos "sujeitos de fronteira", conduzindo-os a uma multiplicidade de caminhos. Assim, o trajeto crítico aqui se faz do Brasil para a África, buscando-se dirigir o olhar para lá com o firme propósito de travar-se um diálogo para que se diminuam as distâncias culturais, 
consolidando-se um contato de forma horizontalizada, fundado na reciprocidade fraterna de uma luta que, infelizmente, não cessa de exigir renovada coragem e força.

\section{Considerações finais}

Uma leitura mais profunda das literaturas moçambicana e afro-brasileira permite vinculá-las aos problemas sociais associados à retextualização do passado de escravidão, com suas marcas indeléveis, no continente africano e no Brasil. Esse fato ajuda a entender a gênese e recrudescimento dessas literaturas que, fugindo de academicismos clássicos, escapam de uma fortuita categorização, podendo-se incluí-las em um escaninho disciplinar à parte do conjunto dos cânones, seguindo-se considerações de Abdala Jr. (2014), o que significa inseri-las no quadro das gnoseologias do sul. Todavia, como a resistência ainda é palavra de ordem, também se resiste às classificações estanques correlatas às genealogias eurocêntricas, portanto, essas literaturas expressam em si mesmas a potencialidade de resistir às formas, aos conteúdos literários disciplinares e aos eixos epistemológicos excludentes disseminados pelo centro.

Na luta premente contra a exclusão política e social, antevê-se a imperiosa necessidade de, na falta de inteireza, na fragmentação, na difração, na dispersão, no deslocamento, reerguer, reconstruir, reescrever, reconstituir a subjetividade de sujeitos afro-brasileiros e moçambicanos, espoliados em suas várias faces, empostando "plurivozes", com gestos atípicos e olhares enviesados. As mulheres moçambicanas e afro-brasileiras, marcadas na pele e debaixo dela com as marcas da dominação patriarcal, colonial, social, procedem à reescritura corporal e identitária desses lugares de invasão. Portanto, Chiziane e Evaristo executam em suas obras a estratégia de revisão dos códigos literários canônicos, optando por reescreverem histórias que partem da autorrepresentação de um feminino que se quer longe da obscuridade.

As fronteiras, longe de significarem apenas a divisão de uma base territorial, ganham dimensão metafórica, aglutinadora de sentidos ideológicos no âmbito da constituição identitária e da resistência cultural. Enquanto névoa, o feminino negro se subverte primeiro no plano da escrita, nas "escrevivências" transgressoras de mulheres que se intrometeram a falar de questões proibi- 
das, abordando o preconceito, a violência doméstica, a vassalagem amorosa, o amor cativo em troca de proteção e segurança, a exploração social, de gênero e sexo, a marginalidade a que estavam submetidas.

Assim, essas autoras escreveram, sobretudo, acerca da aceitação de um eu difratado que se afirma na multiplicidade de seus vários "outros-eus", em face da recusa despersonalizadora da sociedade na construção de projetos, leis, práticas que reforçam a estrutura da exclusão com todas as suas fortalezas e fronteiras. Entende-se que as identidades são difratadas na medida em que os sujeitos se deparam e são contaminados pelos obstáculos criados nas rotas geopolíticas do poder, iniciada no entrecruzar das fronteiras da fome, do desemprego, do analfabetismo, do racismo, do preconceito social, da exploração sexual de gênero, da mortalidade infantil, dentre tantas outras. Todavia, quer queiram ou não, esses indivíduos fraturados ocupam um lugar próprio e se fazem presentes nas calçadas ou paradas das pequenas e grandes cidades, mesmo que à sombra, e investem em uma viagem que lhes dê o direito à crença em um novo presente, uma nova História e um futuro em muito diferente do cenário atual.

A crença foi o único bem trazido por Ponciá na sua longa viagem do campo para a cidade, aspirando a outros destinos, gesto análogo ao de Maria das Dores, que embarca solitária em uma viagem sem rumo à procura dos filhos e pretendendo reencontrar a si mesma, viagem repetida por um sem número de sujeitos difratados em busca do respeito e reconhecimento de suas identidades. Essa crença entende-se aqui sobretudo como o necessário "otimismo crítico" (ABDALA JR., 2014b, p. 127) que demarca a escrita dessas autoras, pautadas na esperança de construção de uma nova realidade de justiça e paz social. Por certo, é muito difícil calcular a duração desse entrecruzar de rios, ribeiros, oceanos, cachoeiras, subjetividades, mares, estradas, asfaltos, chão de barro; apesar disso, "a crença era o único bem que ela havia trazido para enfrentar uma viagem que durou três dias e três noites" (EVARISTO, 2003, p. 35), e ainda será o único bem que uma multidão de excluídos trarão consigo. 


\section{Referências}

ABDALA JÚNIOR, Benjamin. Literatura comparada e relações comunitárias, hoje. São Paulo: Ateliê Editorial, 2012. . Do poder socioeconômico ao simbólico: pensar politicamente o comparatismo literário. In: ABDALA JUNIOR, B. (Org.). Estudos comparados: teoria, crítica e metodologia. São Paulo: Ateliê Editorial, 2014a, p. 133-162.

. Estudos literários e crítica política. Conexão Letras, v. 9, n.12, Porto Alegre, UFRGS, 2014b, p. 123-135.

CAZES, Leonardo. Conceição Evaristo: a literatura como arte da escrevivência. Disponível em: <http://oglobo.globo.com/cultura/livros/conceicao-evaristo-literatura-como-arte-da/escre-vivencia-19682928>. Acesso em 24 dez. 2016.

CHAVES, Rita, SECCO, Carmen, MACÊDO, Tânia (Org.). Brasil / África: como se o mar fosse mentira. São Paulo: UNESP; Luanda: Chá de Caxinde, 2006.

CHIZIANE, Paulina. $O$ alegre canto da perdiz. Lisboa: Caminho, 2008.

DIOGO, Rosalia. Entrevista com Paulina Chiziane: as diversas possibilidades de falar sobre o feminino. In: SECCO, Carmen Lucia Ribeiro Tindó, MIRANDA, Maria Geralda de (Org.). Paulina Chiziane: vozes e rostos femininos. Curitiba: Appris, 2013, p. 361-370.

DIOGO, Rosalia. Paulina Chiziane e Conceição Evaristo: escritas de resistência. In: SIMPÓSIO FAZENDO GÊNERO 9, 2010, Santa Catarina. Anais. Florianópolis: EFSC, 2010, p. 1-8. EVARISTO, Conceição. Ponciá Vicêncio. Belo Horizonte: Mazza, 2003.

. Da representação a auto-representação da Mulher Negra na literatura brasileira. Revista Palmares, Brasília, n. 1, ago. 2005, p. 52-57.

LEITE, Ana Mafalda. Romance de costumes, histórias morais. In: SECCO, Carmen Lucia Ribeiro Tindó; MIRANDA, Maria Geralda de (Org.). Paulina Chiziane: vozes e rostos femininos. Curitiba: Appris, 2013, p. 25-41.

MATA, Inocência. Estudos pós-coloniais: desconstruindo genealogias eurocêntricas. Revista Civitas, Rio Grande do Sul, vol. 14, n. 1, jan. / abr., 2014, p. 2742.

MUDIMBE, Valentin Yves. A invenção de África: gnose, filosofia e a ordem do conhecimento. Luanda: Edições Pedago; Edições Mulemba, 2013.

SANTOS, Boaventura de Sousa. Para além do pensamento abissal: das linhas globais a uma ecologia de saberes. In: SANTOS, Boaventura de Souza; MENESES, Maria Paula (Org.). Epistemologias do Sul. Coimbra: Almedina, 2009, p. 23-71.

SANTOS, Daiana Nascimento dos. Oceano de fronteiras invisíveis: escravidão; migrações e identidades na literatura. Revista Feira Literária Brasil- África, Vitória, v. 1, n. 2, 2016, p. 0111.

SILVA, Milena Matos.Paulina Chiziane, primeira romancista moçambicana. Disponível em: http://ensina.rtp.pt/artigo/paulina-chiziane/. Acesso em 13 dez. 2016. 